\title{
Precisiones sobre la Medea de Eurípides
}

\author{
Clarifications on Euripides' Medea \\ Aida Miguez Barciela \\ Universidad de Zaragoza, España \\ aidamiguez@unizar.es \\ (D) https://orcid.org/0000-0001-6743-4629
}

\begin{abstract}
Resumen:
El artículo examina críticamente el hecho de que los mayores problemas de interpretación los planteen no las tragedias cuyas tramas resultan por lo general desconocidas, sino justamente aquellas que forman parte del acervo cultural del lector común, ya que los prejuicios y las ideas preconcebidas del lector son también mayores. Contando con que nuestra lectura de la Medea de Eurípides está determinada (incluso materialmente) por cómo hayamos comprendido ciertas palabras griegas, el presente trabajo se propone reconsiderar algunos aspectos del programa vengativo de Medea, cuestión estudiada por la autora en publicaciones previas.
\end{abstract}

Palabras Clave: Moral, Conocimiento, Traducción, Interpretación, Campos semánticos.

\section{Abstract:}

This paper examines critically the fact that it is not the tragedy with a plot that is generally unknown to the unspecialized reader, but the one that is part of the cultural heritage of the common reader, that poses the greatest problems of interpretation, since the prejudices and preconceptions of the reader are also greater. Assuming the fact that our reading of Euripides' Medea is determined (even materially) by how we have understood certain Greek words, the present study reconsiders some aspects of Medea's program of revenge, an issue which has been previously studied in other works by the author of this paper.

KEYWORDS: Ethics, Cleverness, Translation, Interpretation, Semantic fields.

1.

Eso que un lector moderno entiende como la "decisión" que pone en marcha la acción de Medea -al verse privada de su estatus como esposa, una mujer prominente "decide" vengarse- ha sido ya tomada antes de que Medea pise la escena. Admitamos por el momento que Medea "ha decidido" no meramente vengarse, sino vengarse de la manera más inesperada, más incisiva, más perfecta y más genial. Veamos cómo lo dice el texto.

Medea finaliza su primer discurso con una petición al coro de mujeres (vv. 259-63 ${ }^{1}$ ). Les pide que guarden silencio en el caso de que "descubra" una "vía" o "estrategia" para "tomarse pago" del esposo "a causa de estos males" -Jasón le ha dado a otra el papel de "señora de la casa”, etcétera-. El coro no desaprueba el proyecto de venganza y concede su silencio.

Tanto el verbo exeurísko como los nombres póros y mekhané forman parte del llamado "campo semántico del conocimiento". Justo después (vv. 282-3), Creonte presenta el decreto de exilio como una manera de proteger a los suyos de una mujer con fama de entendida (experta, sabia) en daños o males diversos. Medea no niega su condición de sabia; es más, su discurso constituye una evidente demostración de su saber.

Creonte lo dice más o menos así: tus lógoi son dulces, pero temo que pudieras proyectar algún daño (bouleúeis: v. 317; cf. ya el verso 37) dentro del pecho (éso phrenôn ${ }^{2}$ ); más fácil resulta guardarse de una mujer (al igual que de un varón) oxuthúmos ("vehemente", "pronto a la cólera") que de una que es sabia y silenciosa (vv. 316-20). No se teme al hombre o a la mujer "impulsivos"; se teme a los "sabios", personajes a los que se 
atribuye la capacidad tanto de confundir con lo que dicen como de callarse lo que piensan. Creonte teme "los discursos", o un cierto uso de "los discursos", de ahí que ordene y prohíba: mè lógous lége (v. 321). ${ }^{3}$

Lo irónico de la escena consiste en el hecho de que Creonte expresa lo que está pasando sin hacerse cargo de que, en verdad, está pasando; y dice lo que teme sufrir en el preciso momento en que lo está sufriendo. Con palabras y con gestos la presunta mujer desvalida ha conseguido ablandar al varón poderoso que se presentó ante ella con la firme intención de desterrarla ("no me iré hasta arrojarte fuera de las fronteras": vv. 275-6).

Medea misma lo confiesa: "he adulado" a "ese" porque me interesaba obtener un provecho y construir algo (tikerdainousan è tekhnoménen: 368-9). Estúpido el que cedió a mis súplicas, pues ha perdido la oportunidad que tenía de haber frustrado mis "planes" desde la raíz (v. 372; ¿los planes están listos ya en este momento?). La "sabia" es "sabia" por su capacidad de esconder con "decires dulces al oído" la "cosa mala" que "proyecta" "dentro del pecho". Se proyecta nada menos que un triple asesinato. Medea se exhorta a sí misma: "no ahorres ninguna de las cosas de las que entiendes siempre que proyectas y construyes. Arrástrate hasta la monstruosidad" (vv. 401-3).

El cómo dice el texto cambia nuestra respuesta inmediata a la pregunta qué dice el texto. Medea no tiene una "decisión" tomada cuando aparece en escena por primera vez: tiene un plan trazado. De lo que se habla en la tragedia de Eurípides no es ni de dilemas psicológicos ni de decisiones morales, sino de saber y proyectar, de construir y planear, actividades que -y esto es algo propio del espíritu del momento ${ }^{4}-$ han caído bajo sospecha. Recordemos: en el nombre Médeia suenan tanto el substantivo médea (los planes, los pensamientos) como el verbo médomai (planear, proyectar); por otro lado, el planear no es en un asunto "de" Medea, sino de "Medea-y-los-dioses" (vv. 1013-14), lo cual confronta al lector moderno con problemas de comprensión interesantes -si los dioses planean, Medea no planea; si todo lo han decidido ellos, entonces ella no ha decidido nada- (Míguez Barciela, 2017, pp. 35-37).

2.

No es solo que los esposos se hayan "desunido", "separado" o "divorciado" (v. 15, v. 27; el verso 13 sugería "unidad"); es que no están de acuerdo en absoluto. Se ha abierto una brecha y se ha entablado una pelea. La palabra es neîkos (vv. 638, 902, 1140), cuyo sentido de rivalidad-pugna por la superioridad-se hace evidente en lo que vemos a continuación.

En el enfrentamiento del segundo episodio, Jasón espera que Medea le conceda que, al menos, ni se ha quedado de brazos cruzados ante la desgracia ${ }^{5}$ ni ha planeado mal (beboúleumai kakôs: v. 567). Al contrario: ha acertado, ha actuado bien, ha resuelto el problema. ${ }^{6}$ A partir de ahora ya podrán "vivir bella/ correctamente" (oikoîmen kalôs: v. 559, cf. práxein kalôs: v. 500). De reconocerlo así, Medea, a diferencia de las mujeres incapaces de distinguir "lo mejor" de "lo peor" (los asuntos de la cama las ofuscan), "se mostraría más sabia" (de lo que "se muestra" o "aparece" ahora).

Conformarse con la nueva boda (ya consumada) y con los planes de futuro (segundos hijos, alianzas para los primeros, etcétera) no depende por lo tanto de la presencia o la ausencia de escrúpulos "morales", sino que depende de acertar o equivocarse, de percepción errónea o verdadera: "que lo bueno nunca te parezca doloroso" (v. 601). ${ }^{7}$

Jasón ha incidido tanto en su condición de sophós como en su habilidad para concebir planes -en ambas cosas rivaliza con Medea-. El verbo bouleúo/boúlomai -planear o proyectar; querer o desear: lo que planeo lo quiero, quiero lo que planeo- no designa en principio ninguna actividad sospechosa. En los poemas homéricos, boulé -substantivo correspondiente al verbo- es tanto el "plan" o el "consejo" como el grupo selecto de guerreros que se reúnen en consejo; es decir, la asamblea de los bouletai o los boulephóroi: los que participan en la boulé, los "consejeros", los que "planean" qué hacer en relación con asuntos importantes. Por otro lado, en Homero es habitual que una nueva secuencia de acciones la introduzca un verso que 
dice aproximadamente así: "entonces en el thumós apareció para mí la mejor boulê". (Así introduce Odiseo el relato de su venganza de Polifemo: Od. 9.318; nótese cuán lejos estamos de una oposición thumósboulé. Por otro lado, poco antes se ha mencionado el "segundo thumós" que descarta un bouleúo previo: vv. 299-302.) Encontrar por fin una solución, descubrir qué es lo mejor que puede hacerse en una determinada situación, diseñar un plan de actuación, todo eso (lo para nosotros "práctico" tanto como lo para nosotros "cognoscitivo") suena a la vez en las palabras griegas boulé/ bouleúma /bouleúo.

Pues bien, el "mostrarse la mejor boulê" forma aquí el contenido de toda la tragedia -la boulé "de" Zeus se mostraba a lo largo de toda la Iliada- (Míguez Barciela, 2016, pp. 42-44, 72-74.). El plan de Medea es, pues, el plano o proyecto de un edificio que va alzándose con cada nueva escena, a la vez que la disputa o rivalidad entre los dos sabios (y sus bouleúmata) va quedando dirimida.

\section{3.}

Medea ha sido franca con Jasón ("vaciaré mi puskhé hablando mal de ti": vv. 473-4). No lo fue en el primer discurso ante el coro de mujeres ${ }^{8}$ ni tampoco en el diálogo con Creonte. En el tercer episodio (encuentro con Egeo) dice la verdad a medias, mostrando una vez más su habilidad en cuanto a qué es oportuno decir y qué es conveniente callar. Sea como fuere, este es el momento en que Medea es apreciada -se hace apreciarcomo interlocutora justamente por su condición de "sabia".

Egeo va en busca de "un tal Piteo" después de haber consultado el oráculo de Apolo. A Delfos viaja quien se encuentra en una situación tal que no sabe qué hacer (el verbo khráomai es central en el campo "oracular"). Según parece, Egeo sigue sin saber qué hacer, pues -así lo dice- el oráculo ha respondido "palabras más sabias de las que un mortal puede comprender" (v. 675). Evidentemente, Egeo mismo es el que no puede comprenderlas, de ahí que vaya en busca de la "mente experta" (sophês phrenós: v. 677) que él mismo no tiene. Medea prefiere dejar como está al desorientado (su interrogatorio sugiere que entiende bastante bien las palabras de Apolo) con el objetivo de arrancarle un compromiso. Ningún Piteo es necesario; ella misma aportará las destrezas oportunas ("no sabes qué hallazgo has hallado: cesaré tu condición carente de hijos y te convertiré en sembrador de descendencia, pues conozco las medicinas adecuadas": vv. 716-18); siempre y cuando -aquí está la ganancia del decir sabio- jure solemnemente no privarla de protección cuando la necesite.

El obstáculo no solo ha sido previsto (matará, se vengará, ¿pero adónde huir después?; esperaremos: vv. 386-91), sino que ha sido ya salvado. La misma condición de sabia que la condenó al destierro garantiza ahora el lugar del que antes carecía: la sophía le abre las puertas de Atenas. Se ha atado un cabo más; se ha situado en el "camino"; ahora hay "esperanza"; por fin ha aparecido el "puerto seguro" en el que "amarrar" los planes (vv. 764-69).

Una vez en este punto -concreción del plan en los versos 774-810; nueva petición de silencio al coro-, la segunda conversación con Jasón resulta completamente distinta de la primera. Medea ya no abrirá su corazón, sino que distraerá a su oponente con palabras que dicen exactamente lo que este quiere oír (disimuló su desprecio de Creonte; disfraza su odio hacia la novia; explota una y otra vez la presunción de debilidad femenina). Y Jasón quiere oír algo así como: yo desvariaba o enloquecía; tú has planeado bien; me doy cuenta de mi mucha "falta de (buen) consejo" (aboulía); tú sabías lo que hacías, yo no estaba en mis cabales; ahora quiero participar en "tus proyectos". En resumen: antes estaba equivocada pero ahora lo he pensado mejor (su beboúleumai rescata el de Jasón).Todo esto en el discurso manipulador de los versos 869-905, soliloquio fingido incluido (cf. también la proyección de Medea en vv. 777-79). Otra vez la rectificación aparente o fingida queda planteada como un cambio no en la valoración moral de una conducta, sino en la percepción correcta de un "estado de cosas" (admisión de un error: ahora también yo digo de A lo mismo que decías tú). Jasón muerde el anzuelo y corrobora: "reconoces, mujer, qué boulé es la vencedora" (vv. 912-13); "has cambiado tu corazón a lo mejor" (el corazón no es la sede de "las emociones", sino que se le atribuye el cambio 
de percepción). Medea ha logrado producir la apariencia que interesa: el nê̂kos es agua pasada y lo ha ganado Jasón.

Hasta aquí -los dos niños llevarán los dos regalos, la novia morirá por los venenos- Medea ejecuta su plan de venganza de forma indirecta y engañosa (ciertas expresiones suenan casi como fórmulas "proféticomágicas": "perecerá horriblemente todo aquel que la tocase”, v. 788; "esto con el dios voy a decirlo", v. 625). Ahora bien, cuando el guión señala que hay que pasar al punto siguiente (cf. la enumeración de los versos 774-96), el que exige que cometa con sus manos un acto sangriento y repulsivo, Medea vacila. Nos situamos así ante los discutidísimos versos 1042-80.

\section{4.}

En los poemas homéricos, eso que a primera vista nos parece una vacilación del personaje es un elemento típico de las así llamadas "escenas de deliberación" (Arend, 1933, pp. 106-113). Se consideran distintas posibilidades, y se las considera en serio, pero esto no es sino una manera de resaltar o subrayar lo que en última instancia ocurre en el poema. Por ejemplo: un guerrero se plantea la posibilidad de buscar refugio entre las multitudes, pero solo para descartarlo con más fuerza inmediatamente después; se consideran distintas opciones, pero solo para que nos demos cuenta de que la acción que sigue las rechaza todas. La actuación se aparta de lo corriente, huye de lo automático, desprecia lo trivial, por eso la admiramos. La escena de deliberación muestra no una "decisión" que se toma, sino una actitud que se retoma. Esto por un lado. Por otro lado, es corriente que la escena de deliberación se cierre con el verso formular “¿pero por qué el thumós dialoga conmigo estas cosas?” (Il. 11.407, 17.92, 22.122, etcétera). Volvamos a Medea.

La dificultad de llegar hasta el final de los planes de venganza se hizo notar repetidamente en las lágrimas, los gemidos, los gestos y los dobleces de Medea, incomprensibles para sus interlocutores, pero no para el "fuera" del poema, no para el oyente/ espectador. El pedagogo no tiene información suficiente para comprender los lamentos de Medea; Jasón se pone en evidencia al no sospechar nada cuando ella esconde su rostro y llora (1006, 1008, 1015-6, 1107-12). Pues bien, durante la despedida de los niños no hay ya interlocutores; el propio thumós es el interlocutor (1056). ¿Por qué el thumós?

La protagonista está preparándose para cometer un doble asesinato con sus propias manos, lo cual exige un ímpetu o ánimo o empuje que hace natural la presencia del thumós (porque necesita reunir energía y coraje, Medea se dirige tanto a su corazón como a su mano: “iármate, corazón!”: v. 1242; “mano mía, ¡coge ya la espada!”: v. 1244). Hay una agonía evidente; la está amenazando el “no serás capaz, no te atreverás” que había anticipado el coro (vv. 856-65), a cuyo canto de advertencia y desaprobación Medea responde ahora ("no soy capaz, amigas": v. 1044). Dos veces se despide de sus planes (v. 1048; se renuncia a los planes en el mismo tirón en que se ruega abstención al thumós, cf. infra), pero esto ocurre solo para que la agonía proporcione la escala de lo que, finalmente, la protagonista si es capaz de hacer: atenerse a su estrategia con rigor militar (los muchos versos del monólogo miden lo mucho que le cuesta hacer lo que se dispone a hacer); con la peculiaridad de que Medea resiste no el terror que infunde el enemigo, sino la ternura que suscitan las miradas ignorantes y las sonrisas inocentes de unos niños que son sus propios niños (lo seductor son las bocas infantiles, el contacto de la piel, los rasgos del rostro, el frescor del aliento; la mirada de despedida realza cada detalle). El "basta ya de ensoñaciones" de Medea no difiere del "basta ya de discursos" con el que los héroes de la Ilíada ponen fin a sus coloquios antes de hacer frente al enemigo (cf. por ejemplo, Il. 22.122).

No es arrebato, es dominio de sí. No es ofuscación, es reconocimiento de lo que hay. Medea reconoce que ha ido demasiado lejos para volver atrás. La cosa ya "está hecha". No hay escapatoria. "Hay que" seguir adelante con el plan. 


\section{5.}

En la Odisea, la expresión kakà phronéontes (y similares) se dice de figuras que traman en secreto actos malos, dañinos o criminales. Ni el "mal" tiene aquí sentido moral, ni las figuras "son malvadas" por idear la mejor manera de hacer daño a sus enemigos (Míguez Barciela, 2014). Nos guste o no nos guste, ni dañar ni matar "están mal" en términos absolutos. En la tragedia de Eurípides, lo que Medea lamenta no es ni su maldad ni su pasión ni su locura (¿cómo hemos traducido la frase kakôs phroneûsa emekhanesámen del verso 1013?, ¿y el verso 1078?, ¿y el 1073?); tampoco su incapacidad para atenerse a las "consideraciones" de su "razón" (si pecamos de anacronismo, que no nos pase desapercibido el hecho de que matar a los niños es lo más "racional" que Medea puede hacer teniendo en cuenta su objetivo). Lo que lamenta de manera inequívoca a lo largo de la tragedia es su tenacidad, obstinación y perseverancia; esto es: su determinación para llevar a cabo el proyecto caiga quien caiga y pase lo que pase.

Si hemos seguido el texto griego hasta este momento, habremos comprobado que unas veces traducíamos el ubicuo adjetivo kakós por "vil" o "abyecto"; kakéy kakosúne por "debilidad” o "cobardía”; kakón por "daño" o "desgracia". De bouleúma ya hemos hablado. Sin embargo, al topar con los versos 1078-1080 las traducciones cambian de rumbo y traducen esta última palabra de manera tal que permita el contraste que nos resulta familiar, pues la traducción está orientada a producir una oposición comprensible para nosotros, pero quizá no para el griego antiguo. ${ }^{9}$ Para ello se desdibuja el uso bastante preciso de bouleúmata hasta este momento, mientras que thumós pasa a ser la emoción que Medea no controla (¿qué emoción exactamente?; los estudios tampoco están de acuerdo). En el cuerpo del monólogo, el thumós es el interlocutor al que se ruega abstención frente al crimen que constituye el último punto del programa trágico (lo cual quiere decir que no presenta conflicto con los bouleúmata -en su empleo preciso, comprometedor-, sino más bien al contrario). Y si de algo se ha hablado en conversaciones anteriores, es de cuán peligrosa resulta no la mujer o el varón oxuthúmos, sino, por el contrario, la sophé y el sophós. Por otra parte, la atetización de estos u otros versos del llamado "gran monólogo" de Medeanos recuerda -si lo habíamos olvidado- que la crítica textual no es neutral en absoluto, sino que se delimita el texto desde un determinado horizonte de expectativas. En este sentido, la tragedia que tenemos ante nosotros nos llega en gran medida ya interpretada.

\section{REFERENCIAS}

Arend, W. (1933). Die typischen Scenen bei Homer. Berlin: Weidmann.

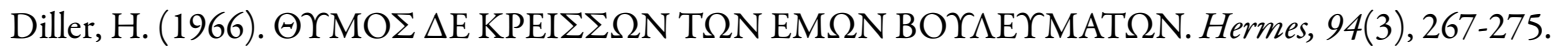

Clarke, M. (2013). Lexical Fields Theory and Greek. En G. K. Giannakis (Ed.), Encyclopedia of Ancient Greek Language and Linguistics. Consulted online on 10 February 2020 http://dx.doi.org/10.1163/2214-448X_eagll_COM_ 00000214 .

Coria, M. (2015). ¿Razón versus pasión? Una lectura del monólogo de Medea (Eurípides, Medea, vv. 1021-1080). Argos, 38, 91-114.

Goldhill, S. (1984). Reading Greek Tragedy. Cambridge: Cambridge University Press.

Latacz, J. (2003). Einführung in die griechische Tragödie. Göttingen: Vandenhoeck \& Ruprecht.

Míguez Barciela, A. (2014). La visión de la Odisea. Madrid: La Oficina de Arte y Ediciones.

Míguez Barciela, A. (2016). Mortal y fúnebre. Leer la Ilíada. Madrid: Dioptrías.

Míguez Barciela, A. (2017). Talar madera. Naturaleza y límite en el pensamiento griego antiguo. Madrid: La Oficina de Arte y Ediciones.

Míguez Barciela, A. (2019). El llanto y la pólis. Madrid: La Oficina de Arte y Ediciones.

Schlesinger, E. (1966). Zu Euripides' Medea. Hermes, 94(1), 26-53. 
Snell, B. (1992). Die Ausdrücke für den Begriff des Wissens in der vor-Platonischen Philosophie. Berlin: Philol. Untersuch. 29 (2. Aufl.).

Stanton, G. R. (1987). The End of Medea’s Monologue: Euripides, Medea 1078-1080. RhM, 130(2), 97-106.

Van Looy, H. (1992). Euripides: Medea. Leipzig: Teubner.

\section{Notas}

1 Sigo la edición de Van Looy (1992). En cuanto a la bibliografía presentada en este artículo, he optado por omitir obras de referencia que han sido ya citadas por mí en trabajos previos, incorporando solo los títulos relevantes para las precisiones que aquí se exponen.

2 La nodriza teme a su señora, entre otras cosas, por su bareîa phrén: v. 38; en los poemas homéricos, el adjetivo barús pesado, fuerte, grave, hondo- suele combinar con "brazos".

3 ¿Es éros realmente el Leitmotiv de "todo el drama”, cf. Latacz (2003) 284? En el epílogo, Medea pone el broche a su venganza no solo derribando una por una las aspiraciones que aún quedan, sino expresando una elocuente acusación final (1392).

4 No solo la palabra sophistés adquiere tintes negativos, sino todo el plexo semántico sophós-sophía-sóphisma, problema que quizá haríamos bien en integrar en la más amplia cuestión de la llamada "crisis del lenguaje” propia del momento, cf. Goldhill (1986).

5 La pasividad o la indiferencia ante una situación adversa habría sido motivo de reproche; pero el argumento es un boomerang: "que nadie me considere mediocre ni débil ni tranquila" (v. 807).

6 Dice algo así como: ¿acaso no he encontrado un remedio para las desgracias sin-remedio que acosan a los refugiados $-\mathrm{y}$ nosotros somos refugiados-? Las palabras son, de nuevo, heúrema y heurísko (v. 553).

7 Estamos familiarizados con condenas "morales" que en griego se expresan con vocabulario "cognitivo": no se condena la mala voluntad, sino la ausencia de conocimiento. En la misma línea, boulé no es "deliberación” tan solo en un sentido práctico, por lo mismo que nóos no es "percepción” meramente cognoscitiva (sino el planear, proyectar, resolver). Las figuras que se distinguen por su capacidad de percepción son las mismas que sobresalen por su capacidad de hacer, tomar determinaciones e, incluso, decir (así Odiseo en Od. 13.296ss.). ¿Debemos, en consecuencia, añadir boulé a ese campo semántico del "conocimiento" que por lo general estudiamos habiéndolo delimitado como tal superponiendo los conceptos que funcionan por defecto para el hablante de una lengua moderna, cf. Snell (1992)? ¿Cómo se establece un “campo semántico” en el caso de una "lengua muerta”? A propósito del campo semántico de lo "sagrado”, Clarke (2013) escribe algo que ningún intérprete debería olvidar: "in our scholarly discourse the very constitution of the field itself has robbed the lexical items within it of their semantic logic".

8 El hecho de que se trate de un discurso manipulativo no nos exime de esforzarnos por comprender las críticas que contiene, en particular por lo que se refiere al hecho de que en la tragedia aparezcan enfáticamente esas que por definición no aparecen: las mujeres, cf. Míguez Barciela (2019).

9 Cf. las distintas traducciones a lenguas modernas recogidas en Coria (2015). 